\title{
Multiple epiphyseal dysplasia type 1
}

INSERM

\section{Source}

INSERM. (1999). Orphanet: an online rare disease and orphan drug data base. Multiple epiphyseal dysplasia type 1. ORPHA:93308

Multiple epiphyseal dysplasia type 1 (MED 1) is a form of multiple epiphyseal dysplasia that is characterized by normal or mild short stature, pain in the hips and/or knees, progressive deformity of extremities and early-onset osteoarthrosis. Specific features to MED 1 include a more pronounced involvement of hip joints and gait abnormality and a shorter adult height. MED1 is allelic to pseudoachondroplasia with which it shares clinical and radiological features. The disease follows an autosomal dominant mode of transmission. 